\title{
Antiangiogenic cytokines as potential new therapeutic targets for resveratrol in diabetic retinopathy
}

This article was published in the following Dove Press journal: Drug Design, Development and Therapy

\author{
Mihaela Popescu' \\ Cătălina Bogdan ${ }^{2}$ \\ Adela Pintea $^{3}$ \\ Dumitrița Rugină ${ }^{3}$ \\ Corina lonescu' \\ 'Department of Biochemistry, \\ University of Medicine and \\ Pharmacy "Iuliu Hațieganu”, Cluj- \\ Napoca, Romania; 'Department of \\ Dermopharmacy and Cosmetics, \\ University of Medicine and \\ Pharmacy "Iuliu Hațieganu”, Cluj- \\ Napoca, Romania; 'Department \\ of Biochemistry, University of \\ Agriculture Sciences and Veterinary \\ Medicine, Cluj-Napoca, Romania
}

Correspondence: Cătălina Bogdan Department of Dermopharmacy and Cosmetics, University of Medicine and Pharmacy "Iuliu Hațieganu", 12 lon Creangă Street, 400010 , Cluj-Napoca, Romania Tel +40740083008 Email catalina.bogdan@umfcluj.ro

\begin{abstract}
Diabetes mellitus (DM) affects $>350$ million people worldwide. With many complications that can reduce the patient's quality of life, vision loss is one of the most debilitating disorders it can cause. Active research in the field of diabetes includes microvascular complications in diabetic retinopathy (DR). Disturbances in the balance of pro-angiogenesis and anti-angiogenesis factors can lead to the progression of DR. The retinal pigment epithelium (RPE) is the outermost layer of the retina, and it is essential in maintaining the visual function. The RPE produces and secretes growth factors as well as protective agents which maintain structural integrity of the retina. Small natural molecules, such as resveratrol, may influence neurotrophic factors of the retina. The pigment epithelium-derived factor (PEDF) and thrombospondin-1 (TSP-1) are secreted by RPE cells. These two proteins inhibit angiogenesis and inflammation in RPE cells. An alteration of their production contributes to various eye diseases. There is a critical balance between two important factors secreted on opposite sides of the RPE: at the basal side, vascular endothelial growth factor (VEGF; acts on the choroidal endothelium) and, on the apical side, PEDF (acts on neurons and photoreceptors). Resveratrol inhibits VEGF expression in human adult RPE cells and limits the development of proliferative vitreoretinopathy, by attenuating transforming growth factor- $\beta 2$-induced wound closure and cell migration. Possible new mechanisms could include PEDF and TSP-1 expression alterations under physiological and pathological conditions. Resveratrol is currently of interest due to its capacity to influence the cell's secretory activity. Some limitations arise from its low bioavailability. Several drug delivery systems are currently tested, promising to improve tissue concentrations. This article reviews biological pathways involved in the pathogenesis of DR that could be influenced by resveratrol. A study of these pathways could identify new potential targets for the reduction of diabetic complications.
\end{abstract}

Keywords: diabetes, retinal secretome, diabetic microvascular complications, phytoalexin

\section{Introduction}

Diabetes mellitus (DM) affected $>350$ million people worldwide in 2013 , and the number is estimated to increase to $>590$ million people by $2035 .{ }^{1}$ Without proper treatment, its complications are serious, starting with ketoacidosis, nonketotic hyperosmolar coma, and continuing with serious vessel damage: microangiopathies (retinopathies, neuropathies, or nephropathies) and macroangiopathies (peripheral vascular diseases, ischemic cardiomyopathy, or cerebrovascular accidents). In the long term, these can be an important cause of mortality. One of the leading causes of blindness in adults aged 20-74 years is diabetic retinopathy (DR). ${ }^{2}$ In DR, progressive damage to the retina 
occurs when fragile blood vessels break, causing swelling of the retinal tissue and cell loss.

Current treatments are trying to achieve strict glycemic control. A recent European epidemiological study showed that, despite modern protocols, 39\% of young adults diagnosed with diabetes in the last 10 years develop DR, and the need for protection from vision loss is greater than ever. ${ }^{3}$ In 2012, Yau et $\mathrm{al}^{4}$ studied the global prevalence and risk factors of DR. The conclusion of the study was an overall prevalence of $34.6 \%$ DR, 7\% proliferative DR (PDR), $6.8 \%$ diabetic macular edema (DME), and $10.2 \%$ visionthreatening DR. DR was present in nearly all diabetic patients after a certain period, with a higher prevalence in type 1 diabetes. ${ }^{4}$ Once diagnosed, DR was directly linked to insufficient metabolic control; the strongest predicting risk factors for retinopathy are $\mathrm{HbA} 1 \mathrm{c}$ and glycated albumin..$^{5}$ A study performed in 2010 revealed that approximately one third of 285 million people diagnosed with diabetes showed signs of DR, and the number is expected to rise further. ${ }^{6}$

Standard care for PDR includes panretinal photocoagulation (PRP) and more recently anti-vascular endothelial growth factor (VEGF) injections. ${ }^{7-9}$ PRP was initiated as a treatment option in the 1960s and was documented as beneficial over time. It is used to improve the retinal circulation, allowing more oxygen to reach the retina and limiting the formation and release of pro-angiogenic cytokines. ${ }^{10}$ Laser treatment can reduce the rates of vision loss by up to $50 \%$ over 3 years. ${ }^{11}$ Anti-VEGF injections have been recently used to treat PDR and proved to be a promising potential alternative. A multicenter randomized clinical trial comparing ranibizumab versus PRP recently concluded that ranibizumab has similar effects in improving visual acuity at a 2-year follow-up. Ranibizumab proved superiority over PRP when it came to safety concerns. It showed fewer side effects, such as peripheral visual field loss or contrast sensitivity loss. Although intravitreal ranibizumab of $0.5 \mathrm{mg}$ is more expensive than PRP by almost $60 \%$, its reduced adverse effects may support its future use. ${ }^{7}$

DME affects $\sim 30 \%$ of patients with DR and is a major factor leading to vision loss. ${ }^{12}$ It can occur at any stage of DR, and the risk increases with the severity of the disease: $3 \%$ cases with mild nonproliferative diabetic retinopathy (NPDR), 38\% cases with moderate-to-severe NPDR, and $71 \%$ cases with PDR. ${ }^{13}$ Intravitreal VEGF inhibitors are currently the standard care for DME. Following the results of the Ranibizumab for Edema of the mAcula in Diabetes (READ-2) study after 6 months, 2 years, and 3 years, ranibizumab has become a frequently used first-line therapy agent for DME. ${ }^{14-16}$ Intravitreal steroid implants (such as dexamethasone or fluocinolone acetonide) exert their antiinflammatory action, with minimum side effects, and have a nonspecific anti-VEGF effect. For this reason, they are currently reimbursed by different health care systems in the management of DME. ${ }^{12}$ There is a lack of consensus on the management of patients with DME who underwent vitrectomy. For this reason, current studies evaluate the outcome of steroid implants, such as fluocinolone acetonide, on visual acuity and patient compliance, suggesting that further research and real-life data collection might support the use in current practice, as well as in earlier DME development stages. ${ }^{17}$ Refractory cases of DME to ranibizumab or dexamethasone could be switched to aflibercept. Studies comparing the two agents (ranibizumab and aflibercept) offer controversial results. Evidence suggests that the two agents are equal in terms of efficiency, with aflibercept having the advantage of fewer injection numbers required. ${ }^{18}$ One case-control study on a 69 -year-old man with bilateral DME showed a significant improvement with aflibercept over ranibizumab treatment. A plausible explanation might be the additional capacity of aflibercept to target the placental growth factor-1, a member of the VEGF family. ${ }^{19}$ Given the fact that aflibercept is well tolerated, has a comfortable dosage regimen, and has a complex mechanism of action, it might be considered for DME first-line treatment. ${ }^{20}$ Future prospective studies need to focus on a long-term follow-up regarding safety and efficacy when switching from one antiVEGF agent to another. ${ }^{21}$

With strong level 1 evidence supporting anti-VEGF injections over PRP for the treatment of DME, new data suggest that it may become a key player in the treatment of DR and PDR. ${ }^{22}$ Anti-VEGF agents may slow down the development of DME in preproliferative eyes, but data are scarce regarding DR progression after anti-VEGF injections are discontinued. Some important issues need more clarification: cost, prospective studies on other VEGF agents, and new sustained-release devices. While PRP remains the standard care for PDR, combination therapy could be a valid alternative: anti-VEGF initially followed by PRP.?

The Early Treatment Diabetic Retinopathy Study classification covers the full range of retinopathies and is the most complex one. ${ }^{11}$ In 2002, the Global Diabetic Retinopathy Project Group proposed a version designed to be used for population screening ${ }^{23}$ (Table 1). ${ }^{24}$

In the past few years, natural polyphenols, found in plants, including vegetables and fruits, have gained interest, and medical nutrition therapy is emerging as a tailored therapeutic approach that could reduce the risk of developing complications in chronic diseases such as type 2 diabetes. 
Table I Classification of DR severity

\begin{tabular}{llll}
\hline International clinical DR disease severity scale & & \\
\hline Mild NPDR & Moderate NPDR & Severe NPDR & PDR \\
\hline Microaneurysms & More than just & $>20$ intraretinal hemorrhages in each of & One or more: \\
only & microaneurysms & 4 quadrants & Neovascularization \\
& Less than severe & OR & Vitreous/preretinal \\
& NPDR & Definite venous bleeding in 2+ quadrants & hemorrhage \\
& OR & & \\
& Prominent IRMA in I+ quadrant and no PDR & \\
\hline
\end{tabular}

Notes: Adapted from: The Royal College of Ophthalmologists. Diabetic retinopathy guidelines; December 20I2. Available from: https://www.rcophth.ac.uk/wp-content/ uploads/20I4/I2/20I3-SCI-30I-FINAL-DR-GUIDELINES-DEC-20I2-updated-July-20I3.pdf. @ The Royal College of Ophthalmologists 20I2. All rights reserved. ${ }^{24}$

Abbreviations: DR, diabetic retinopathy; IRMA, intraretinal microvascular abnormalities; NPDR, nonproliferative diabetic retinopathy; PDR, proliferative diabetic retinopathy.

The search for new substances to diminish vision loss due to DM includes natural products, with resveratrol emerging as a promising "player." ${ }^{25}$ This polyphenolic phytoalexin has beneficial properties according to several in vitro and in vivo studies. Such benefits include antidiabetic activity, ${ }^{26}$ antiinflammatory effect, ${ }^{27}$ anti-neovascularization protection, ${ }^{28}$ and prevention of DR. ${ }^{29}$

\section{Biochemical mechanisms involved in DR}

Diabetes, in all its forms, is characterized mainly by hyperglycemia. During its course, the development of microvascular pathology is likely. Figure 1 shows the four main mechanisms of hyperglycemia-induced damage that are considered responsible for the occurrence of DR: increased polyol pathway flux, increased advanced glycation endproducts (AGEs) formation, increased hexosamine pathway flux, and activation of protein kinase C (PKC). Each of these pathways leads to an abnormal function and production of the cells, resulting in early apoptosis, progressive capillary occlusion, extracellular matrix overproduction, and deposition of plasma proteins. ${ }^{30,31}$ These pathways to DR are associated with an overproduction of reactive oxygen species (ROS), and they are discussed next.

\section{Increased polyol pathway flux}

This two-step metabolic pathway is an important contributor to DR. The key enzyme of the polyol pathway is aldose reductase (AR), a cytosolic, rate-limiting, monomeric oxidoreductase. The second enzyme involved

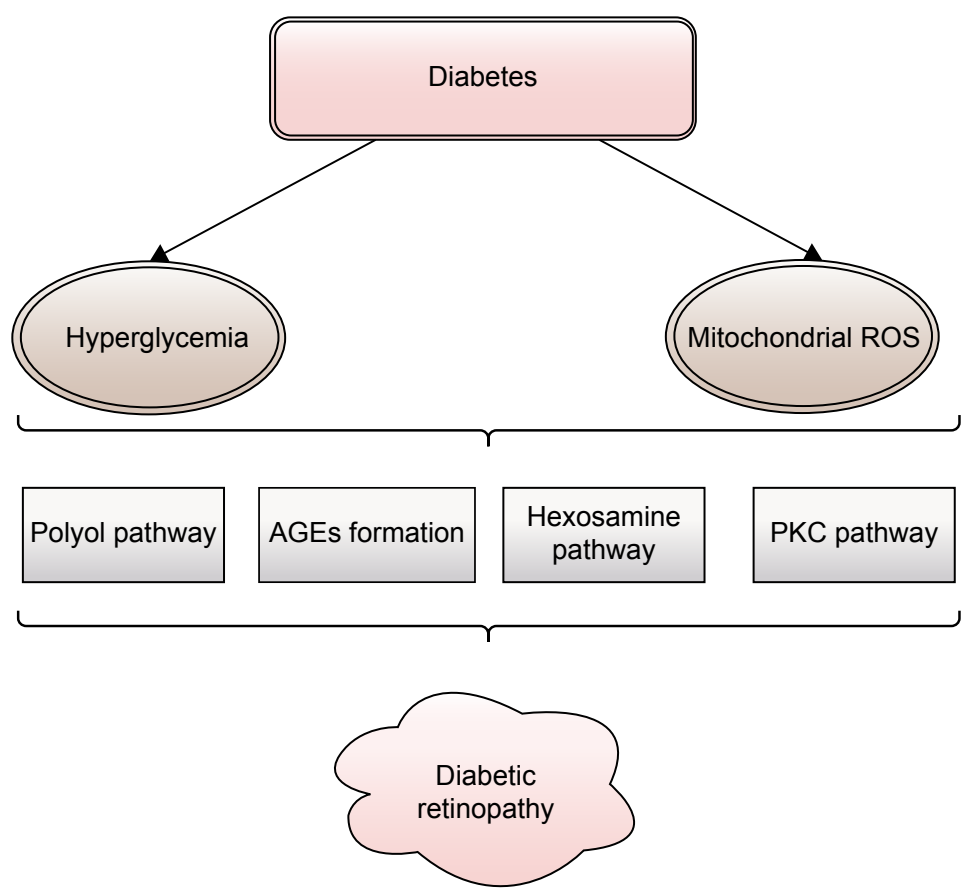

Figure I The main mechanisms of hyperglycemia-induced damage considered responsible for the occurrence of diabetic retinopathy: increased polyol pathway flux, increased AGEs formation, increased hexosamine pathway flux, and activation of PKC.

Notes: Adapted from Safi SZ, Qvist R, Kumar S, Batumalaie K, Ismail IS. Molecular mechanisms of diabetic retinopathy, general preventive strategies, and novel therapeutic targets. Biomed Res Int. 2014;2014:80I269. Copyright (C) 2014 Sher Zaman Safi et al. ${ }^{31}$

Abbreviations: AGEs, advanced glycation end-products; PKC, protein kinase C; ROS, reactive oxygen species. 

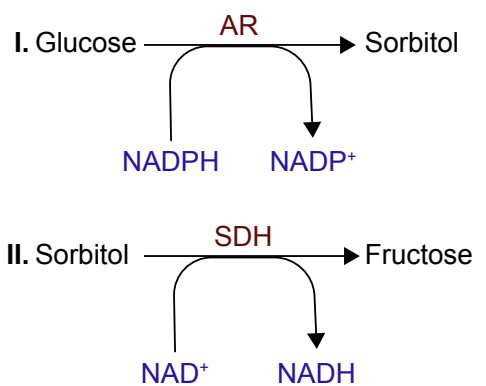

Figure 2 Schematic presentation of stages of polyol pathway: (I) glucose reduction to sorbitol by AR (using NADPH as a cofactor) followed by (II) sorbitol oxidation to fructose by $\mathrm{SDH}$ (using $\mathrm{NAD}^{+}$as a cofactor).

Notes: Adapted from Safi SZ, Qvist R, Kumar S, Batumalaie K, Ismail IS. Molecular mechanisms of diabetic retinopathy, general preventive strategies, and novel therapeutic targets. Biomed Res Int. 2014;20I4:80I269. Copyright @ 2014 Sher Zaman Safi et al. ${ }^{31}$ Abbreviations: $\mathrm{AR}$, aldose reductase; $\mathrm{NAD}^{+}$, nicotinamide adenine dinucleotide oxidized; NADH, nicotinamide adenine dinucleotide - reduced; NADP+ ${ }^{+}$, nicotinamide adenine dinucleotide phosphate - oxidized; NADPH, nicotinamide adenine dinucleotide phosphate - reduced; SDH, sorbitol dehydrogenase.

is sorbitol dehydrogenase (SDH). Under euglycemic conditions, AR has a low affinity for glucose, but a high capacity of conversion, reducing it to sorbitol (with nicotinamide adenine dinucleotide phosphate - reduced [NADPH] as a cofactor) at a low level. SDH has a high affinity, but a low capacity to oxidize sorbitol to fructose (using nicotinamide adenine dinucleotide - oxidized [ $\left.\mathrm{NAD}^{+}\right]$as a cofactor) independent of its concentration within physiological values (Figure 2). In diabetic patients, the polyol pathway activity increases in the retina, causing local accumulation of sorbitol and osmotic damage. Other factors that contribute to further damage are a decrease in cytosolic NADPH and an increase in cytosolic nicotinamide adenine dinucleotide - reduced $(\mathrm{NADH}) / \mathrm{NAD}^{+}$ under hyperglycemic conditions. ${ }^{31}$

The alteration in the NADH (NADPH)/NAD ${ }^{+}\left(\mathrm{NADP}^{+}\right)$ ratios reduces the activity of glutathione reductase, lessening the cell's ability to respond to ROS accumulation, while the increase in $\mathrm{NADH} / \mathrm{NAD}^{+}$mimics hypoxia in the tissue (Figure 3)..$^{31,32}$

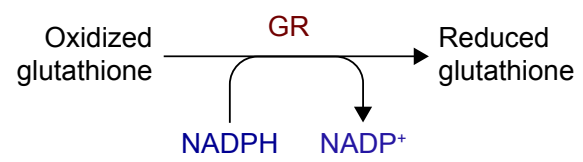

Figure 3 Polyol pathway changes induced in $\mathrm{NADH}(\mathrm{NADPH}) / \mathrm{NAD}^{+}\left(\mathrm{NADP}^{+}\right)$ratios with the decrease of GR, leading to ROS accumulation and tissue impairments. Notes: Adapted from Safi SZ, Qvist R, Kumar S, Batumalaie K, Ismail IS. Molecular mechanisms of diabetic retinopathy, general preventive strategies, and novel therapeutic targets. Biomed Res Int. 20I4;20I4:80I269. Copyright (C) 2014 Sher Zaman Safi et al. ${ }^{31}$

Abbreviations: GR, glutathione reductase; $\mathrm{NAD}^{+}$, nicotinamide adenine dinucleotide - oxidized; NADH, nicotinamide adenine dinucleotide - reduced; $\mathrm{NADP}^{+}$, nicotinamide adenine dinucleotide phosphate - oxidized; NADPH, nicotinamide adenine dinucleotide phosphate - reduced; ROS, reactive oxygen species.

\section{Increased AGEs formation}

Prolonged hyperglycemia amplifies certain physiological nonenzymatic processes, resulting in the formation of a complex and irreversible group of compounds termed AGEs. ${ }^{33}$ Glucose derivatives enter a condensation reaction (Maillard reaction) with the amine residues of proteins, nucleic acids, or lipids and follow a series of chemical rearrangements, leading to structural and functional degradation that in turn leads to mural pericyte loss and vascular lesions. ${ }^{33}$ Markers of AGEs formation and accumulation are found in high concentrations in diabetic patients in retinal vessels, in vitreous tissues, and in other tissues affected by hyperglycemia. ${ }^{34,35}$ There are three general mechanisms through which AGEs target cells: modification of intracellular proteins resulting in an altered function, modification of matrix components resulting in an abnormal interaction between each other and with cellular protein receptors (integrins), and modification of plasma proteins, which bind to specific AGEs receptors (receptor for AGE [RAGE]) inducing an increased production of ROS (Figure 4). ${ }^{30}$ RAGE ligation activates transcription factor nuclear factor- $\mathrm{\kappa B}(\mathrm{NF}-\mathrm{\kappa B})$, which in turn induces abnormal gene expression, as well as NADPH oxidase that contributes to ROS formation and pericyte apoptosis. ${ }^{36-38}$

The polyol and the increased AGEs formation pathways intertwine. The fructose produced through the polyol pathway undergoes further transformations, generating glycation agents that can produce AGEs. ${ }^{39}$ These factors increase VEGF

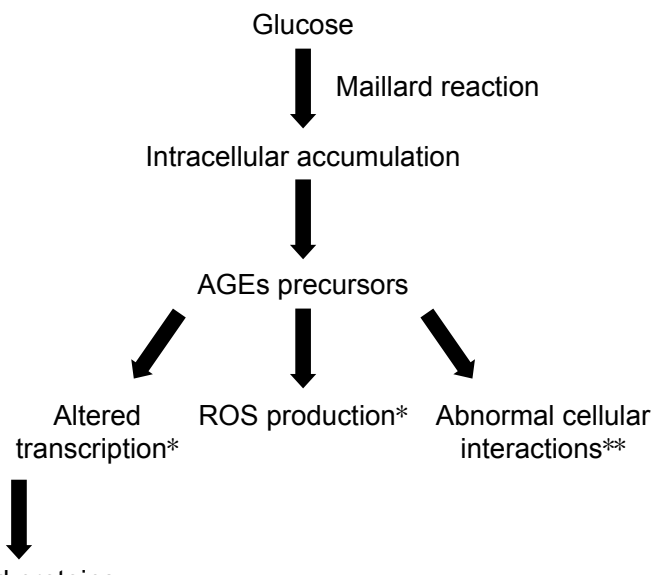

Altered proteins

Figure 4 Schematic presentation of AGEs formation and the pathways through which AGEs target cells: altered function of intracellular proteins; abnormal interaction between matrix components and protein receptors (integrins); increased production of ROS due to abnormal interaction between plasma proteins and specific AGE receptors.

Notes: *Intracellular actions; **extracellular actions. Original figure; adapted from data from Brownlee. ${ }^{30}$

Abbreviations: AGEs, advanced glycation end-products; ROS, reactive oxygen species. 
gene transcription, mediating capillaries hyperpermeability and intercellular adhesion molecule (ICAM) production and influencing retinal capillary leukocyte adherence. ${ }^{40}$

\section{Increased hexosamine pathway flux}

This hyperglycemia-induced pathway impacts the development of diabetic complications. In its glycolytic pathway, glucose is normally converted to glucose-6-phosphate and then isomerized to fructose-6-phosphate (F-6-P). In hyperglycemic conditions, F-6-P is diverted from glycolysis to $\mathrm{N}$-acetylglucosamine-6-phosphate by glutamine-fructose-6 -phosphate aminotransferase (GFAT). The conversion continues with end-products such as proteoglycans and $O$-linked glycoproteins (cytoplasmic and nuclear proteins). ${ }^{41}$ Inhibition of GFAT blocks the increased transcription of transforming growth factor-alpha, transforming growth factor-beta 1 (TGF- $\beta 1$ ), inducers of cell proliferation and differentiation, and plasminogen activator inhibitor-1 (PAI-1), involved in cell differentiation, growth, and apoptosis. ${ }^{31,41}$ Through the hexosamine pathway, hyperglycemia induces changes in gene expression and protein function, that contribute to the pathogenesis of DR (Figure 5).

\section{Activation of PKC}

$\mathrm{PKC}$ is a family of multifunctional serine/threonine kinases divided into three groups: classical (PKC- $\alpha$, PKC- $\beta 1$, PKC- $\beta 2$, and PKC- $\gamma$ ), novel (PKC- $\delta$, PKC- $\varepsilon$, PKC- $\eta / 1$, and $\mathrm{PKC}-\theta$ ), and atypical (PKC $\zeta$ and $\mathrm{PKC} \lambda / \mathrm{l}){ }^{42}$ Studies showed that intracellular hyperglycemia increases de novo diacylglycerol synthesis, a lipid second messenger that activates the classical PKC isoforms ${ }^{43}$ Hyperglycemia can also activate $\mathrm{PKC}$ isoforms through the ligation of AGEs receptors ${ }^{44}$ and increase flux through the polyol pathway. ${ }^{45}$ Oxidants such as $\mathrm{H}_{2} \mathrm{O}_{2}$ can activate $\mathrm{PKCs}$ through a mechanism unrelated to lipid second messengers ${ }^{46}$ through mitochondrial superoxide induced by hyperglycemia. ${ }^{47}$ PKC activation alters the bioavailability of nitric oxide, affects VEGF expression (by decreasing the expression of prostacyclin and increasing the expression of thromboxane), ${ }^{48}$ and directly increases albumin and other macromolecules permeability through barriers formed by endothelial cells. ${ }^{49,50}$ It has also been linked to mitogen-activated protein kinase activation, a factor that increases gene expression (Figure 6). ${ }^{43,51}$

In previous studies, it has been stated that PKC activation is responsible for major changes resulting in diabetes complications: vascular permeability, increased blood

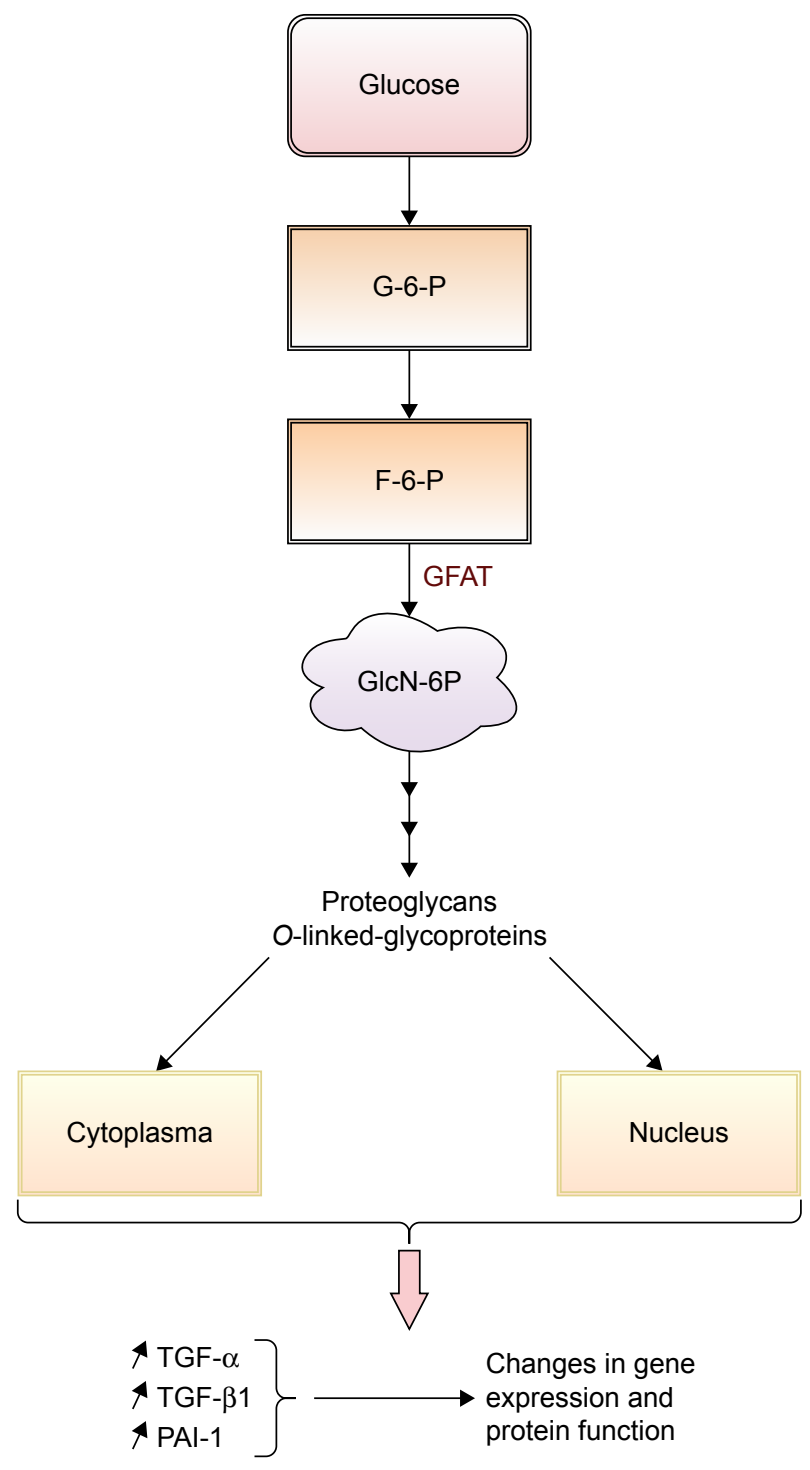

Figure 5 Schematic presentation of the contribution of increased hexosamine pathway flux in pathogenesis of DR.

Note: Original figure; adapted from data from Giacco and Brownlee.41

Abbreviations: DR, diabetic retinopathy; F-6-P, fructose-6-phosphate; G-6-P, glucose6-phosphate; GFAT, glutamine-fructose-6-phosphate aminotransferase; GlcN-6P, $\mathrm{N}$-acetylglucosamine-6-phosphate; PAI-I, plasminogen activator inhibitor-I; TGF- $\alpha$, transforming growth factor-alpha; TGF- $\beta$ I, transforming growth factor-beta I.

flow, extracellular matrix protein accumulation, membrane hypertrophy, leukocyte adhesion, angiogenesis, and apoptosis. ${ }^{52-54}$

\section{Hyperglycemia-induced pathological changes in the retina}

These four biochemical pathways linked to an altered glucose metabolism disturb the balance of pro-angiogenesis and antiangiogenesis factors involved in the progression of DR. An increase in the polyol pathway flux correlates with 


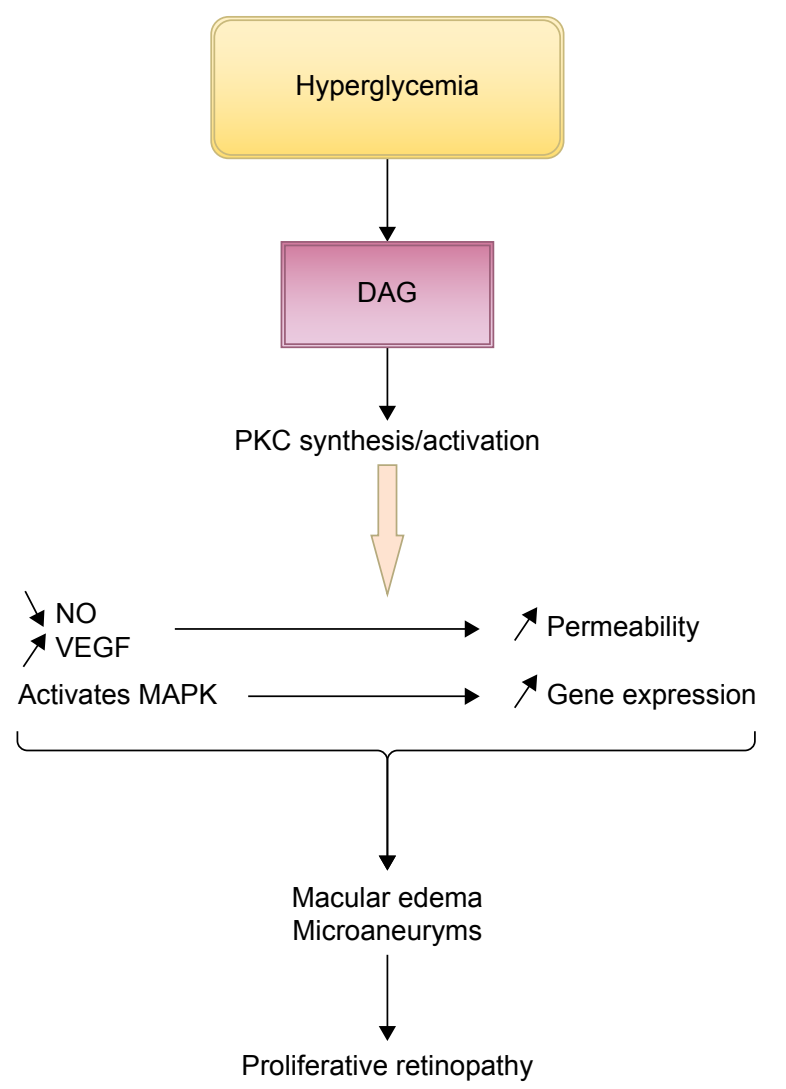

Figure 6 Schematic presentation of the contribution of PKC activation to the development of diabetic retinopathy.

Note: Original figure; adapted from data from Geraldes and King. ${ }^{43}$

Abbreviations: DAG, diacylglycerol; MAPK, mitogen-activated protein kinase; NO, nitric oxide; PKC, protein kinase C; VEGF, vascular endothelial growth factors.

tissue hypoxia, which in turn triggers VEGF production. ${ }^{55}$ A recent in vitro study also showed an increase in VEGF-C secretion by AGEs, followed by the increased effect of VEGF-A, underlining the role of AGEs in the onset of retinal neovascularization. ${ }^{56}$
The hexosamine pathway increases TGF- $\beta 1$ synthesis through the GFAT enzyme. Inhibition of this pathway lowers TGF- $\beta 1$ synthesis and bioactivity associated with the development of DR. ${ }^{57,58}$ Overactivity of PKC also alters VEGF production causing retinal vascular dysfunctions, while in vivo studies showed an association between platelet-derived growth factor (PDGF) resistance and the increase of retinal PKC- $\delta$ in diabetic mice. Inhibition of the survival signaling pathway of PDGF causes retinal cell apoptosis. ${ }^{54}$

For this reason, new pharmacological treatments are based on understanding the molecular mechanisms that occur and the factors involved in the process. The retinal pigment epithelium (RPE) is the outermost layer of the retina, and it has several functions, making it essential in assuring our visual function: transporting nutrients and metabolism products through the blood-retinal barrier, light absorption, secretion, and immunity. This monolayer of pigmented cells is well documented in producing and secreting certain types of growth factors, as well as protective agents, which maintain structural integrity. RPE cells secrete proteins at two opposite poles: at the apical cell side or at the basal side. ${ }^{59}$ The angiogenic/antiangiogenic factor ratio balances the cellular redox status (or cellular oxidative status), with $>55$ differentially secreted proteins in hyperglycemic conditions. ${ }^{60}$ Table 2 lists some of them.

\section{New potential targets}

Research in the field of DR has focused mainly on proangiogenic compounds, while protective factors have received less attention. In healthy adults, endogenous antiangiogenic factors, such as thrombospondin-1 (TSP-1), pigment epithelium-derived factor (PEDF), and angiostatin, ${ }^{61-63}$

Table 2 Proteins secreted from RPE cells

\begin{tabular}{|c|c|c|}
\hline Cytokines secreted by RPE & Functions & Role in DR \\
\hline VEGF & Proinflammatory and angiogenic molecule & Regulates neovascularization \\
\hline Transforming growth factor- $\beta$ & Controls proliferation and cellular differentiation & Alters growth factor's balance \\
\hline Insulin-like growth factor-I & $\begin{array}{l}\text { Promotes cellular growth and insulin-like } \\
\text { metabolic effects }\end{array}$ & Autocrine/paracrine regulation of proliferation \\
\hline Platelet-derived growth factor & $\begin{array}{l}\text { Regulates cell growth and division and pericyte } \\
\text { viability }\end{array}$ & $\begin{array}{l}\text { Promotes neovascularization and traction of } \\
\text { epiretinal membranes }\end{array}$ \\
\hline $\begin{array}{l}\text { Lens epithelium-derived growth } \\
\text { factor }\end{array}$ & Growth and survival factor & $\begin{array}{l}\text { Enhances survival in RPE cells when challenged } \\
\text { by oxidative stress }\end{array}$ \\
\hline TIMP (TIMP-I and TIMP-3) & Involved in extracellular matrix degradation & Plays a role in preneovascularization \\
\hline Pigment epithelium-derived factor & $\begin{array}{l}\text { Antiangiogenic, anti-tumorigenic, and } \\
\text { neurotrophic protein }\end{array}$ & $\begin{array}{l}\text { Fails to inhibit cell proliferation and maintain } \\
\text { the retinal structure }\end{array}$ \\
\hline Ciliary neurotrophic factor & $\begin{array}{l}\text { Interferes with MAPK, PI3K, and NF-KB } \\
\text { signaling pathways }\end{array}$ & Increases RPE cell survival \\
\hline Fibroblast growing factor & Induces VEGF expression in retinal vascular cells & May represent a source of neural regeneration \\
\hline
\end{tabular}

Note: Data adapted from Weight et al. ${ }^{58}$

Abbreviations: DR, diabetic retinopathy; MAPK, mitogen-activated protein kinase; NF- $\mathrm{KB}$, nuclear factor- $\mathrm{KB}$; PI3K, phosphoinositide 3-kinase; RPE, retinal pigment epithelium; TIMP, tissue inhibitor of matrix metalloproteinase; VEGF, vascular endothelial growth factors. 
maintain the ocular vasculature under control. These proteins modulate cellular proliferation, migration, differentiation, and apoptosis and influence the oxidative state and phagocytic activity of RPE cells.

TSP-1 induced angiogenesis in vivo at low concentrations, ${ }^{64,65}$ whereas in higher concentrations, inhibition occurred. This homotrimeric matricellular glycoprotein is produced by various cell types. At retinal level, it supports RPE cell structure and inhibits vascular endothelial cell adhesion. ${ }^{66}$ TSP-1 production in the eye is dramatically reduced in diabetes. ${ }^{75}$

PEDF is found in the human eye from early embryonic stages ${ }^{58}$ and different studies confirm its presence in RPE cells. ${ }^{67-69}$ This homotrimeric matricellular glycoprotein proved to be a more potent inhibitor of endothelial cell migration caused by angiogenic inducers compared with TSP-1 and angiostatin $;^{70}$ one of its mechanisms includes the inhibition of NADPH oxidase activity induced by AGEs. ${ }^{71,72}$

Sheibani et al demonstrated that high glucose levels affect TSP-1 production by endothelial cells in vitro with the appearance of retinal vasculopathies. ${ }^{73}$ An in vivo study performed on Akita/+ male mice deficient in TSP-1 demonstrated an increase in pathological vascular changes; in addition, Akita/+ PEDF-deficient mice also showed an increase in acellular capillaries. ${ }^{74}$ Other previous studies measured the levels of TSP-1 and PEDF from vitreous samples of diabetic and nondiabetic patients. The diabetic group had lower levels of TSP-1 and a higher molecular weight PEDF isoform. ${ }^{75}$

PEDF has been showed to inhibit the development of $\mathrm{DR}$, proving to be a good candidate for the treatment of DR. However, practical pharmaceutical applications are limited due to its structure. Finding a natural compound which could modulate its expression might be a solution to rebalance the oxidant status of the cell.

Identification of new mechanisms of action for natural antiangiogenic compounds is very important and the normal step to take in case of resistance to long-term use of angiogenic inhibitors.

\section{Natural therapeutic agents}

It is important, when considering a new therapeutic strategy, to target a mechanism independent of VEGF since present anti-VEGF drugs have shown similar efficacy and only an independent mechanism of action could improve outcomes, rather than an additional suppression of this pathway.

Resveratrol, or 3,5,4'-trihydroxystilbene, is a phytoalexin produced by plants as a response to stress, fungal infections, injuries, or ultraviolet radiation. This polyphenol belongs to the class of stilbenes and has been isolated for the first time from Veratrum grandiflorum. It has made the subject of $>50,000$ scientific articles over the past decade only, and its ability to target intracellular molecules and processes is being intensively studied. Polygonum cuspidatum, Vitis vinifera, different Vaccinium species, and Arachis hypogaea are among the known sources of resveratrol. ${ }^{76}$

Resveratrol modulates various pathways, including $\mathrm{PKC},{ }^{77}$ rebalances the cellular oxidative status, ${ }^{78,79}$ and is proved to be a powerful activator of sirtuin 1 (SIRT-1), an angiogenesis key regulator ${ }^{80}$ In vitro and in vivo studies showed multiple mechanisms of action of resveratrol, with a preponderant targeting of angiogenic factors: it reduces VEGF accumulation via the activation of AMPK, ${ }^{81}$ suppresses TGF- $\beta 2$-induced cell migration in ARPE-19 cells, ${ }^{82}$ and inhibits PDGF-induced RPE cell migration, ${ }^{83}$ slowing the process of degradation of the blood-retina barrier. A double-blind, randomized, placebo-controlled study on 44 healthy subjects revealed that a daily intake of $400 \mathrm{mg}$ of resveratrol for a month reduced endothelial activation and vascular inflammation quantified by the reduction in the expression of interleukin-8 and cell adhesion molecules (ICAM-1 and vascular cell adhesion molecule-1). ${ }^{84}$ In addition, daily administration of $8 \mathrm{mg}$ of resveratrol for 6 months to patients undergoing primary cardiovascular disease prevention, followed by an increase to 16 $\mathrm{mg}$ of resveratrol for another 6 months, significantly reduced the levels of C-reactive protein, tumor necrosis factor- $\alpha$, and PAI-1, improving the inflammatory status. ${ }^{85}$

Published literature documents the inhibitory effect of resveratrol on pro-angiogenic protein molecules. Research on the influence of resveratrol on antiangiogenic cytokines is scarce. One study was performed on human retinal pigment epithelial cells and failed to reveal a positive influence on PEDF secretion (enzyme-linked immunosorbent assay). ${ }^{86}$ Another study explored SIRT-1 activation in Müller glial cells and found that resveratrol enhances antiangiogenic factors by increasing gene expression of PEDF and TSP-1 by 1.4 -fold and 1.5-fold, respectively. Respiratory syncytial virus upregulation of PEDF and TSP-1 may have antichoroidal neovascularization properties ${ }^{87} \mathrm{~A}$ high-glucose environment decreases SIRT-1 activity and promotes matrix metalloproteinase-9 (MMP-9) activation through NF- $\kappa \mathrm{B}$ pathway. ${ }^{88}$ MMPs contribute to the development of tissue injury and inflammation at various sites, including the retina. ${ }^{89}$ A study using a mouse model of retinopathy investigated MMP effects on PEDF proteolysis and found that it abolishes PEDF protective activity and retinal survival. ${ }^{90}$ Knowing the neuroprotective role of resveratrol against 


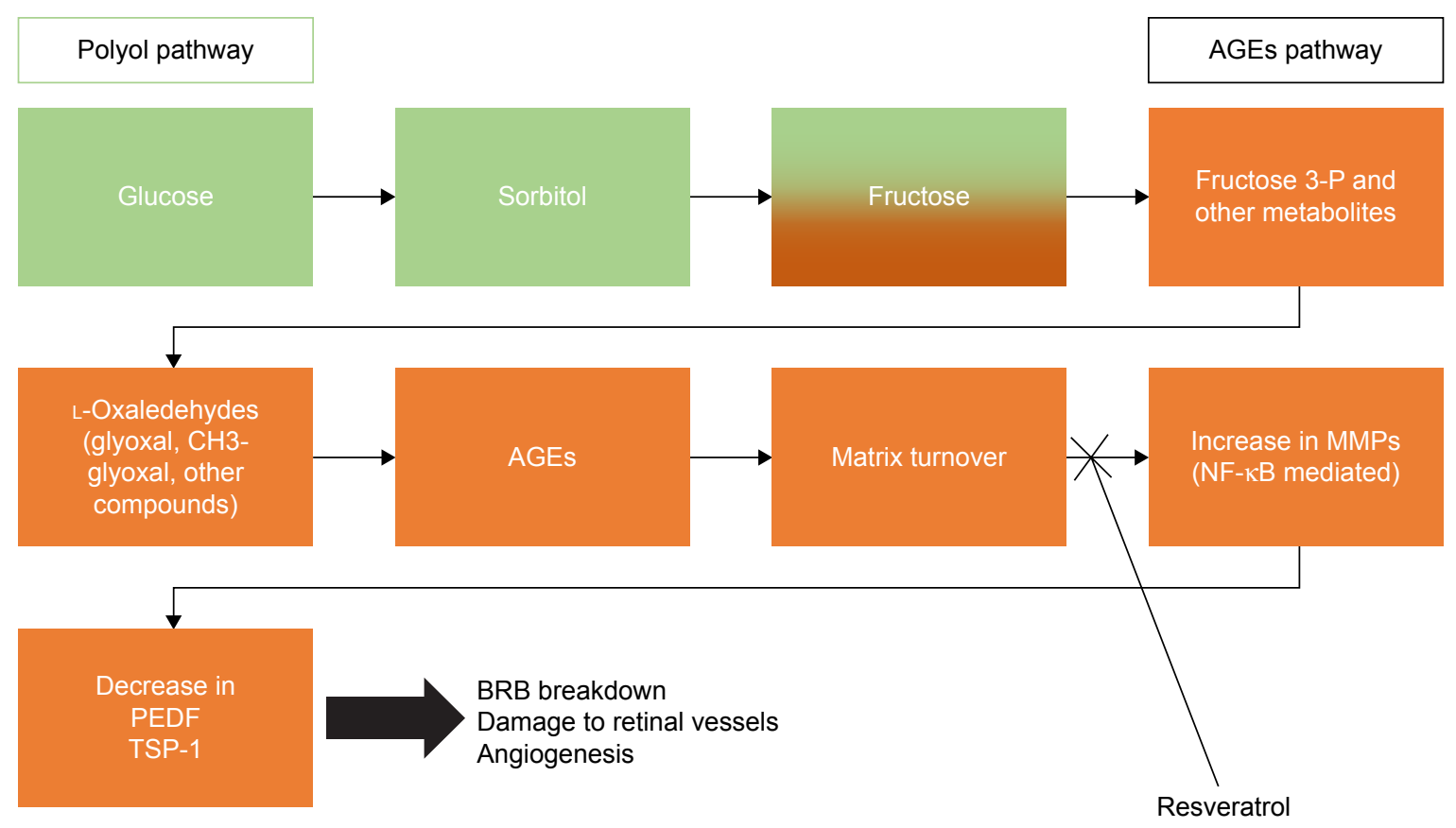

Figure 7 Schematic presentation of a possible mechanism of action for resveratrol in the development of diabetic retinopathy.

Abbreviations: AGEs, advanced glycation end-products; BRB, blood-retinal barrier; MMPs, matrix metalloproteinases; NF- KB, nuclear factor- $\kappa B$; PEDF, pigment epitheliumderived factor; TSP-I, thrombospondin-I.

ischemia, its interaction with MMPs was studied, and it revealed an inhibitory activity by interaction with MMP active site residues..$^{91}$ A possible pathway to investigate could be the enhancement of PEDF and TSP-1 by resveratrol through the inhibition of MMPs, bearing in mind that PEDF expression increases TSP-1 production ${ }^{92}$ and promotes retinal survival. Figure 7 illustrates possible mechanisms of action for resveratrol in the development of DR.

\section{Delivery systems overview on oral pharmaceutical forms}

Resveratrol is a chemically instable compound with poor water solubility, being well absorbed ( $75 \%)$, but with a low bioavailability $(<1 \%),{ }^{93}$ which limits its activity and biological effects. Following oral administration, the biological half-life is short ( $8-14$ minutes), and in vitro evidence revealed undetected levels in targeted tissues. ${ }^{94}$

Short-term studies reported minor adverse effects, most of them being gastrointestinal side effects. ${ }^{95}$ Still, the large number of in vitro effects of free resveratrol remains controversial, since it is rapidly metabolized, achieving a negligible concentration in the bloodstream.

Lately, numerous formulations have been investigated to increase the solubility and the bioavailability of resveratrol or to obtain targeted/prolonged delivery. ${ }^{96-98}$ Those formulations contain different forms of resveratrol varying from pro-drug administration to nanodelivery systems. ${ }^{94}$ Among the large variety of nanoformulations reported, liposomal preparations are biocompatible because the addition of organic solvents such as DMSO in the preparation step is excluded. ${ }^{100}$ Encapsulation of the active substance in liposomes prevents the inactivation through cis-trans isomerization and leads to an improved chemical stability of resveratrol. ${ }^{100,102}$ Several studies showed a targeted action for liposomes, resulting in an enhanced delivery with superior efficacy compared with free compounds. ${ }^{100,103,104}$

Moreover, combined delivery systems such as liposomes loaded with resveratrol encapsulated in alginate, alginatesucrose, and alginate-chitosan microbeads ${ }^{98}$ and liposomes loaded with resveratrol-cyclodextrin inclusion complexes ${ }^{100}$ were reported, as having an improved drug release profile. Nanoemulsions have been developed to enhance the solubility and bioavailability of lipophilic compounds or to protect the antioxidant properties of resveratrol. ${ }^{101,112,113}$ According to Sessa et al, nanoemulsions sustain the controlled release of the encapsulated resveratrol, ${ }^{101}$ along with the increase of its half-life. ${ }^{114}$ Recently, self-emulsifying drug delivery systems have been documented to increase the solubility and bioavailability of resveratro $1{ }^{96}$ and to enhance the intestinal permeation. ${ }^{115}$

Other carriers, such as nanoparticles, were extensively studied, and different systems for the delivery of resveratrol 
have been designed. Solid nanoparticles were prepared using protein molecules such as zein, ${ }^{99}$ gliadin, ${ }^{105} \beta$-lactoglobulin, ${ }^{106}$ gelatin, ${ }^{110}$ or other biodegradable polymers such as poly(DLlactide-co-glycolide) ${ }^{107}$ and polyethylene glycol-polylactic acid. ${ }^{108,109}$ Encapsulation of the drug in nanoparticles protects it against degradation, increases bioavailability, and ensures sustained release. Solid lipid nanoparticles and nanostructured lipid carriers have been proposed as alternative carriers for targeted delivery of resveratrol, showing advantages such as stability and high entrapment efficiency over classical nanoemulsions and liposomes. ${ }^{97,111}$

To date, a large number of nanodelivery systems have been studied, but more research is needed to transfer in vivo all potential beneficial effects of resveratrol. An ideal delivery system for resveratrol should increase solubility, stability, and bioavailability, should prolong release with targeted delivery to improve its therapeutic efficiency, and should reduce the doses administered.

\section{Summary and future directions}

There is an increasing interest toward natural compounds, especially those presenting antioxidant, anti-inflammatory, or immunomodulatory properties. Resveratrol is of high interest for its many mechanisms of action that can provide researchers with new data in molecular biology. DR is a priority eye disease on the VISION 2020 list, for prevention and treatment. Despite laser photocoagulation as the standard care, intravitreal drugs as alternative options, and vitreoretinal surgery for severe cases of DR, this vision-threatening condition remains a continuous clinical challenge.

This review aimed at underlining the complexity of the pathogenesis of diabetic microvascular complications, with four main mechanisms being directly responsible for the oxidant/antioxidant cellular imbalance and tissue damage. Each pathway contains intermediate products produced through other reactions involved in this pathological process. The retinal secretome is sensitive to glycemic fluctuations, and because of the accumulation of deleterious and highly reactive products, proteins secreted in the retina are overproduced or inhibited depending on their overall actions.

The need for targeting new mechanisms in the development of DR is more evident than ever. The retina produces pro-angiogenic factors as well as protective molecules in its attempt to balance the cellular media and to assure the tissue survival. This review underlines the importance of further studying natural protective agents and how they can influence or even rise the levels of "good" proteins in specific tissues that can protect our eyes from diabetic complications.

\section{Acknowledgments}

This research was financially supported by the University of Medicine and Pharmacy, Cluj-Napoca, Romania (Grant number 7690/73/15.04.2016). The work of Rugină Dumitrița was supported by Executive Agency for Higher Education, Research, Development and Innovation Funding (PN-II-RUTE-2014-4-1135, 14/01.10.2015). The authors thank Royal College of Ophthalmologists for allowing the use of data from Diabetic Retinopathy Guidelines.

\section{Disclosure}

The authors report no conflicts of interest in this work.

\section{References}

1. Kharroubi AT, Darwish HM. Diabetes mellitus: the epidemic of the century. World J Diabetes. 2015;6(6):850-867.

2. Cheung N, Mitchell P, Wong TY. Diabetic retinopathy. Lancet. 2010;376(9735):124-136.

3. Henricsson M, Nyström L, Blohmé G, et al. The incidence of retinopathy 10 years after diagnosis in young adult people with diabetes. Results from the nationwide population-based Diabetes Incidence Study in Sweden (DISS). Diabetes Care. 2003;26(2):349-354.

4. Yau JW, Rogers SL, Kawasaki R, et al. Global prevalence and major risk factors of diabetic retinopathy. Diabetes Care. 2012;35(3):556-564.

5. Nathan DM, McGee P, Steffes MW, Lachin JM; DCCT/EDIC Research Group. Relationship of glycated albumin to blood glucose and $\mathrm{HbA} 1 \mathrm{c}$ values and to retinopathy, nephropathy, and cardiovascular outcomes in the DCCT/EDIC study. Diabetes. 2014;63(1):282-290.

6. Lee R, Wong TY, Sabanayagam C. Epidemiology of diabetic retinopathy, diabetic macular edema and related vision loss. Eye Vis (Lond). 2015;2:17.

7. Li X, Zarbin MA, Bhagat N. Anti-vascular endothelial growth factor injections: the new standard of care in proliferative diabetic retinopathy? Dev Ophthalmol. 2017;60:131-142.

8. Blinder KJ, Dugel PU, Chen S, et al. Anti-VEGF treatment of diabetic macular edema in clinical practice: effectiveness and patterns of use (ECHO Study Report 1). Clin Ophthalmol. 2017;11:393-401.

9. Stitt AW, Lois N, Medina RJ, Adamson P, Curtis TM. Advances in our understanding of diabetic retinopathy. Clin Sci (Lond). 2013;125(1): $1-17$.

10. Kinshuck D. Proliferative retinopathy. Available from: http://www. diabeticretinopathy.org.uk/proliferative.html\#1. Accessed January 14, 2018.

11. Early Treatment Diabetic Retinopathy Study Research Group. ETDRS Report No. 7: Early Treatment Diabetic Retinopathy Study design and baseline patient characteristics. Ophthalmology. 1991;98:741-756.

12. Dugel PU, Hillenkamp J, Sivaprasad S, et al. Baseline visual acuity strongly predicts visual acuity gain in patients with diabetic macular edema following anti-vascular endothelial growth factor treatment across trials. Clin Ophthalmol. 2016;10:1103-1110.

13. Diabetic Retinopathy with Diabetic Macular Edema. Available from: https://www.genentech-forum.com/content/dam/gene/managedcare/ forum/pdfs/Disease-Information/diabetic-retinopathy-with-diabeticmacular-edema-disease-state-overview.pdf. Accessed January 14, 2018.

14. Nguyen QD, Shah SM, Heier JS, et al. Primary end point (six months) results of the Ranibizumab for Edema of the mAcula in Diabetes (READ-2) study. Ophthalmology. 2009;116(11):2175.e1-2781.e1.

15. Nguyen QD, Shah SM, Khwaja AA, et al. Two-year outcomes of the ranibizumab for edema of the mAcula in diabetes (READ-2) study. Ophthalmology. 2010;117(11):2146-2151. 
16. Do DV, Nguyen QD, Khwaja AA, et al. Ranibizumab for edema of the macula in diabetes study: 3-year outcomes and the need for prolonged frequent treatment. JAMA Ophthalmol. 2013;131(2):139-145.

17. Meireles A, Goldsmith C, El-Ghrably I, et al. Efficacy of $0.2 \mu \mathrm{g} / \mathrm{day}$ fluocinolone acetonide implant (ILUVIEN) in eyes with diabetic macular edema and prior vitrectomy. Eye (Lond). 2017;31(5):684-690.

18. Fouda SM, Bahgat AM. Intravitreal aflibercept versus intravitreal ranibizumab for the treatment of diabetic macular edema. Clin Ophthalmol. 2017;11:567-571

19. Vandekerckhove KR. Aflibercept versus ranibizumab for treating persistent diabetic macular oedema. Int Ophthalmol. 2015;35(4): 603-609.

20. Korobelnik JF, Wolf S. An overview of intravitreal aflibercept in diabetic macular oedema. Eur Ophthal Rev. 2015;9(1):37-41.

21. Herbaut A, Fajnkuchen F, Qu-Knafo L, Nghiem-Buffet S, Bodaghi B, Giocanti-Auregan A. Switching to aflibercept in diabetic macular edema not responding to ranibizumab and/or intravitreal dexamethasone implant. J Ophthal. 2017;2017:8035013.

22. Stewart MW. A review of ranibizumab for the treatment of diabetic retinopathy. Ophtalmol Ther. 2017;6(1):33-47.

23. Wilkinson CP, Ferris FL, Klein RE, et al. Proposed international clinical diabetic retinopathy and diabetic macular edema disease severity scales. Ophthalmology. 2003;110(9):1677-1682.

24. The Royal College of Ophthalmologists. Diabetic retinopathy guidelines. Available from: https:/www.rcophth.ac.uk/wp-content/ uploads/2014/12/2013-SCI-301-FINAL-DR-GUIDELINES-DEC2012-updated-July-2013.pdf. Accessed May 13, 2017.

25. Nanjan MJ, Betz J. Resveratrol for the management of diabetes and its downstream pathologies. Eur Endocrinol. 2014;10(1):31-35.

26. Sharma S, Misra CS, Arumugam S, et al. Antidiabetic activity of resveratrol, a known SIRT1 activator in a genetic model for type-2 diabetes. Phytother Res. 2011;25(1):67-73.

27. Kubota S, Ozawa Y, Kurihara T, et al. Roles of AMP-activated protein kinase in diabetes-induced retinal inflammation. Invest Ophthalmol Vis Sci. 2011;52(12):9142-9148.

28. Hua J, Guerin KI, Chen J, et al. Resveratrol Inhibits Pathologic Retinal Neovascularization in Vldlr ${ }^{-/}$mice. Invest Ophthalmol Vis Sci. 2011;52(5):2809-2816.

29. Soufi FG, Mohammad-Nejad D, Ahmadieh H. Resveratrol improves diabetic retinopathy possibly through oxidative stress - nuclear factor КB - apoptosis pathway. Pharmacol Rep. 2012;64(6):1505-1514.

30. Brownlee M. Biochemistry and molecular cell biology of diabetic complications. Nature. 2001;414(6865):813-820.

31. Safi SZ, Qvist R, Kumar S, Batumalaie K, Ismail IS. Molecular mechanisms of diabetic retinopathy, general preventive strategies, and novel therapeutic targets. Biomed Res Int. 2014;2014:801269.

32. Frey T, Antonetti DA. Alterations to the blood-retinal barrier in diabetes: cytokines and reactive oxygen species. Antioxid Redox Signal. 2011;15(5):1271-1284.

33. Sharma Y, Saxena S, Mishra A, Saxena A, Natu SM. Advanced glycation end products and diabetic retinopathy. J Ocul Biol Dis Infor. 2012; 5(3-4):63-69.

34. Goh SY, Cooper ME. Clinical review: the role of advanced glycation end products in progression and complications of diabetes. $J$ Clin Endocrinol Metab. 2008;93(4):1143-1152.

35. Stitt AW. Advanced glycation: an important pathological event in diabetic and age related ocular disease. Br J Ophthalmol. 2001;85(6):746-753.

36. Ibrahim AS, El-Remessy AB, Matragoon S, et al. Retinal microglial activation and inflammation induced by amadori-glycated albumin in a rat model of diabetes. Diabetes. 2011;60(4):1122-1133.

37. Yamagishi S, Matsui T, Nakamura K, Ueda S, Noda Y, Imaizumi T. Pigment epithelium-derived factor (PEDF): its potential therapeutic implication in diabetic vascular complications. Curr Drug Targets. 2008;9(11): 1025-1029

38. Yamagishi S, Matsui T. Advanced glycation end products (AGEs), oxidative stress and diabetic retinopathy. Curr Pharm Biotechnol. 2011; 12(3):362-368.
39. Mathebula SD. Polyol pathway: a possible mechanism of diabetes complications in the eye. Afr Vision Eye Health. 2015;74(1):1-5.

40. Stitt AW. AGEs and diabetic retinopathy. Invest Ophthalmol Vis Sci. 2010;51(10):4867-4874.

41. Giacco F, Brownlee M. Oxidative stress and diabetic complications. Circ Res. 2010;107(9):1058-1070.

42. Protein kinase $\mathrm{C}$ signaling interactive pathway. Available from: https:// www.cellsignal.com/contents/science-cst-pathways-ca-camp-and-lipidsignaling/protein-kinase-c-signaling-interactive-pathway/pathwayskinase-c. Accessed July 20, 2017.

43. Geraldes $P$, King GL. Activation of protein kinase C isoforms \& its impact on diabetic complications. Circ Res. 2010;106(8):1319-1331.

44. Portilla D, Dai G, Peters JM, Gonzalez FJ, Crew MD, Proia AD. Etomoxir-induced PPARalpha-modulated enzymes protect during acute renal failure. Am J Physiol Renal Physiol. 2000;278(4): F667-F675

45. Kamiya H, Nakamura J, Hamada Y, et al. Polyol pathway and protein kinase C activity of rat Schwannoma cells. Diabetes Metab Res Rev. 2003;19(2):131-139.

46. Li M, Lin YF, Palchik GA, Matsunaga S, Wang D, Chen BP. The catalytic subunit of DNA-dependent protein kinase is required for cellular resistance to oxidative stress independent of DNA double-strand break repair. Free Radic Biol Med. 2014;76:278-285.

47. Nishikawa T, Edelstein D, Du XL, et al. Normalizing mitochondrial superoxide production blocks three pathways of hyperglycaemic damage. Nature. 2000;404(6779):787-790.

48. Ding Y, Vaziri ND, Coulson R, Kamanna VS, Roh DD. Effects of simulated hyperglycemia, insulin, and glucagon on endothelial nitric oxide synthase expression. Am J Physiol Endocrinol Metab. 2000;279(1):E11-E17.

49. Andus KL, Raub TL. Chapter 10. Mechanisms of increased endothelial permeability. In: Biological Barriers to Protein Delivery. New York: Plenum Press; 1993:254-256.

50. Sukriti S, Tauseef M, Yazbeck P, Mehta D. Mechanisms regulating endothelial permeability. Pulm Circ. 2014;4(4):535-551.

51. Rosse C, Linch M, Kermorgant S, Cameron AJ, Boeckeler K, Parker PJ. $\mathrm{PKC}$ and the control of localized signal dynamics. Nat Rev Mol Cell Biol. 2010;11(2):103-112.

52. PKC-DRS2 Group, Aiello LP, Davis MD, et al. Effect of ruboxistaurin on visual loss in patients with diabetic retinopathy. Ophthalmology. 2006; 113(12):2221-2230.

53. Das Evcimen N, King GL. The role of protein kinase C activation and the vascular complications of diabetes. Pharmacol Res. 2007; 55(6):498-510.

54. Geraldes P, King GL. Activation of protein kinase $C$ isoforms and its impact on diabetic complications. Circ Res. 2010;106(8):1319-1331.

55. Ramakrishnan S, Anand V, Roy S. Vascular endothelial growth factor signaling in hypoxia and inflammation. J Neuroimmune Pharmacol. 2014;9(2):142-160.

56. Puddu A, Sanguineti R, Durante A, Nicolò M, Viviani GL. Vascular endothelial growth factor-C secretion is increased by advanced glycation end-products: possible implication in ocular neovascularization. Mol Vis. 2012;18:2509-2517.

57. Kitada M, Zhang Z, Mima A, King GL. Molecular mechanisms of diabetic vascular complications. J Diabetes Investig. 2010;1(3):77-89.

58. Weight C, Friess U, Brodbeck K, Haring HU, Schleicher ED. Glutamine:fructose-6-phosphate aminotransferase enzyme activity is necessary for the induction of TGF- $\beta 1$ and fibronectin expression in mesangial cells. Diabetologia. 2003;46(6):852-855.

59. Strauss O. The retinal pigment epithelium in visual function. Physiol Rev. 2005;85(3):845-881.

60. Chen YH, Chou HC, Lin ST, Chen YW, Lo YW, Chan HL. Effect of high glucose on secreted proteome in cultured retinal pigmented epithelium cells: its possible relevance to clinical diabetic retinopathy. J Proteomics. 2012;77:111-128.

61. Ponnalagu M, Subramani M, Jayadev C, Shetty R, Das D. Retinal pigment epithelium-secretome: a diabetic retinopathy perspective. Cytokine. 2017;95:126-135. 
62. Qazi Y, Maddula S, Ambati BK. Mediators of ocular angiogenesis. J Genet. 2009;88(4):495-515.

63. Nyberg P, Xie L, Kalluri R. Endogenous inhibitors of angiogenesis. Cancer Res. 2005;65(10):3967-3979.

64. Lawler PR, Lawler J. Molecular basis for the regulation of angiogenesis by thrombospondin-1 and -2. Cold Spring Harb Perspect Med. 2012; 2(5):a006627.

65. Kazerounian S, Yee KO, Lawler J. Thrombospondins in cancer. Cell Mol Life Sci. 2008;65(5):700-712.

66. Isenberg JS, Ridnour LA, Perruccio EM, Espey MG, Wink DA, Roberts DD. Thrombospondin-1 inhibits endothelial cell responses to nitric oxide in a cGMP-dependent manner. Proc Natl Acad Sci U S A. 2005;102(37):13141-13146.

67. Karakousis PC, John SK, Behling KC, et al. Localization of pigment epithelium derived factor (PEDF) in developing and adult human ocular tissues. Mol Vis. 2001;7:154-163.

68. Kozulin P, Natoli R, Bumsted O’Brien KM, Madigan MC, Provis JM. The cellular expression of antiangiogenic factors in fetal primate macula. Invest Ophthalmol Vis Sci. 2010;51(8):4298-4306.

69. Becerra SP, Fariss RN, Wu YQ, Montuenga LM, Wong P, Pfeffer BA. Pigment epithelium-derived factor in the monkey retinal pigment epithelium and interphotoreceptor matrix: apical secretion and distribution. Exp Eye Res. 2004;78(2):223-234.

70. Johnston EK, Francis MK, Knepper JE. Recombinant pigment epithelium-derived factor PEDF binds vascular endothelial growth factor receptors 1 and 2. In Vitro Cell Dev Biol Anim. 2015;51(7): 730-738.

71. Yamagishi S, Nakamura K, Matsui T, et al. Pigment epitheliumderived factor inhibits advanced glycation end product-induced retinal vascular hyperpermeability by blocking reactive oxygen speciesmediated vascular endothelial growth factor expression. J Biol Chem. 2006;281(29):20213-20220.

72. Yamagishi S, Matsui T, Nakamura K, et al. Pigment-epitheliumderived factor suppresses expression of receptor for advanced glycation end products in the eye of diabetic rats. Ophthalmic Res. 2007; 39(2):92-97.

73. Sheibani N, Sorenson CM, Cornelius LA, Frazier WA. Thrombospondin-1, a natural inhibitor of angiogenesis, is present in vitreous and aqueous humor and is modulated by hyperglycemia. Biochem Biophys Res Commun. 2000;267(1):257-261.

74. Wang S, Gottlieb JL, Sorenson CM, Sheibani N. Modulation of thrombospondin 1 and pigmented epithelium-derived factor levels in vitreous fluid of patients with diabetes. Arch Ophthalmol. 2009; 127(4):507-513.

75. Sorenson CM, Wang S, Gendron R, Paradis H, Sheibani N. Thrombospondin-1 deficiency exacerbates the pathogenesis of diabetic retinopathy. J Diabetes Metab. 2013;Suppl 12.

76. Pintea AM, Rugină DO. Resveratrol and the human retina. In: Preedy V, editor. Handbook of Nutrition, Diet and the Eye. London: Academic Press; 2014:481-491.

77. Pany S, Majhi A, Das J. PKC activation by resveratrol derivatives with unsaturated aliphatic chain. PLoS One. 2012;7(12):e52888.

78. Spanier G, Xu H, Xia N, et al. Resveratrol reduces endothelial oxidative stress by modulating the gene expression of superoxide dismutase 1 (SOD1), glutathione peroxidase 1 (GPx1) and NADPH oxidase subunit (Nox4). J Physiol Pharmacol. 2009;60(Suppl 4):111-116.

79. Mokni M, Elkahoui S, Limam F, Amri M, Aouani E. Effect of resveratrol on antioxidant enzyme activities in the brain of healthy rat. Neurochem Res. 2007;32(6):981-987.

80. Zhang H, He S, Spee C, Ishikawa K, Hinton DR. SIRT1 mediated inhibition of VEGF/VEGFR2 signaling by resveratrol and its relevance to choroidal neovascularization. Cytokine. 2015;76(2): $549-552$.

81. Nagai N, Kubota S, Tsubota K, Ozawa Y. Resveratrol prevents the development of choroidal neovascularization by modulating AMPactivated protein kinase in macrophages and other cell types. J Nutr Biochem. 2014;25(11):1218-1225.
82. Chen CL, Chen YH, Tai MC, Liang CM, Lu DW, Chen JT. Resveratrol inhibits transforming growth factor- $\beta 2$-induced epithelialto-mesenchymal transition in human retinal pigment epithelial cells by suppressing the Smad pathway. Drug Des Devel Ther. 2017;11:163-173.

83. Chan CM, Chang HH, Wang VC, Huang CL, Hung CF. Inhibitory effects of resveratrol on PDGF-BB-induced retinal pigment epithelial cell migration via PDGFR $\beta$, PI3K/Akt and MAPK pathways. PLoS One. 2013;8(2):e56819.

84. Agarwal B, Campen MJ, Channell MM, et al. Resveratrol for primary prevention of atherosclerosis: clinical trial evidence for improved gene expression in vascular endothelium. Int J Cardiol. 2013;166(1): 246-248.

85. Tome-Carneiro J, Gonzalvez M, Larrosa M, et al. One-year consumption of a grape nutraceutical containing resveratrol improves the inflammatory and fibrinolytic status of patients in primary prevention of cardiovascular disease. Am J Cardiol. 2012;110(3):356-363.

86. Nagineni CN, Raju R, Nagineni KK, et al. Resveratrol suppresses expression of VEGF by human retinal pigment epithelial cells: potential nutraceutical for age-related macular degeneration. Aging Dis. 2014; 5(2):88-100.

87. Ishida T, Yoshida T, Shinohara K, et al. Potential role of sirtuin 1 in Müller glial cells in mice choroidal neovascularization. PLoS One. 2017;12(9): 0183775.

88. Kowluru RA, Santos JM, Zhong Q. Sirt1, a Negative regulator of matrix metalloproteinase-9 in diabetic retinopathy. Invest Ophthalmol Vis Sci. 2014;55(9):5653-5660.

89. Tucker B, Klassen H, Yang L, Chen DF, Young MJ. Elevated MMP expression in the MRL mouse retina creates a permissive environment for retinal regeneration. Invest Ophthalmol Vis Sci. 2008;49(4):1686-1695.

90. Notari L, Miller A, Martínez A, et al. Pigment epithelium-derived factor is a substrate for matrix metalloproteinase type 2 and type 9: implications for downregulation in hypoxia. Invest Ophthalmol Vis Sci. 2005;46(8):2736-2747.

91. Pandey AK, Bhattacharya P, Shukla SC, Paul S, Patnaik R. Resveratrol inhibits matrix metalloproteinases to attenuate neuronal damage in cerebral ischemia: a molecular docking study exploring possible neuroprotection. Neural Regen Res. 2015;10(4):568-575.

92. Nelius T, Martinez-Marin D, Hirsch J, et al. Pigment epitheliumderived factor expression prolongs survival and enhances the cytotoxicity of low-dose chemotherapy in castration-refractory prostate cancer. Cell Death Dis. 2014;5:e1210.

93. Cottard CH, Nivet-Antoine V, Beaudeux JL. Review of recent data on the metabolism, biological effects, and toxicity of resveratrol in humans. Mol Nutr Food Res. 2014;58(1):7-21.

94. Singh G, Pai RS. Recent advances of resveratrol in nanostructured based delivery systems and in the management of HIV/AIDS. J Control Release. 2014;194:178-188.

95. Brown VA, Patel KR, Viskaduraki M, et al. Repeat dose study of the cancer chemopreventive agent resveratrol in healthy volunteers: safety, pharmacokinetics, and effect on the insulin-like growth factor axis. Cancer Res. 2010;70(22):9003-9011.

96. Balata GF, Essa EA, Shamardl HA, Zaidan SH, Abourehab MA. Self-emulsifying drug delivery systems as a tool to improve solubility and bioavailability of resveratrol. Drug Des Devel Ther. 2016;10: $117-128$

97. Neves AR, Lúcio M, Martins S, Lima JL, Reis S. Novel resveratrol nanodelivery systems based on lipid nanoparticles to enhance its oral bioavailability. Int J Nanomedicine. 2013;8:177-187.

98. Balanč B, Trifković K, Đorđević V, et al. Novel resveratrol delivery systems based on alginate-sucrose and alginate-chitosan microbeads containing liposomes. Food Hydrocoll. 2016;61:832-842.

99. Huang X, Dai Y, Cai J, et al. Resveratrol encapsulation in core-shell biopolymer nanoparticles: impact on antioxidant and anticancer activities. Food Hydrocoll. 2017;64:157-165.

100. Soo E, Thakur S, Qu Z, Jambhrunkar S, Parekh HS, Popat A. Enhancing delivery and cytotoxicity of resveratrol through a dual nanoencapsulation approach. J Colloid Interface Sci. 2016;462:368-374. 
101. Sessa M, Balestrieri ML, Ferrari G, et al. Bioavailability of encapsulated resveratrol into nanoemulsion-based delivery systems. Food Chem. 2014;147:42-50.

102. Coimbra M, Isacchi B, van Bloois L, et al. Improving solubility and chemical stability of natural compounds for medicinal use by incorporation into liposomes. Int J Pharm. 2011;416(2):433-442.

103. Lu XY, Hu S, Jin Y, Qiu LY. Application of liposome encapsulation technique to improve anti-carcinoma effect of resveratrol. Drug Dev Ind Pharm. 2012;38(3):314-322.

104. Wang XX, Li YB, Yao HJ, et al. The use of mitochondrial targeting resveratrol liposomes modified with a dequalinium polyethylene glycoldistearoylphosphatidyl ethanolamine conjugate to induce apoptosis in resistant lung cancer cells. Biomaterials. 2011;32(24):5673-5687.

105. Joye IJ, Davidov-Pardo G, Ludescher RD, McClements DJ. Fluorescence quenching study of resveratrol binding to zein and gliadin: towards a more rational approach to resveratrol encapsulation using water-insoluble proteins. Food Chem . 2015;185:261-267.

106. Kim JH, Park EY, Ha HK, et al. Resveratrol-loaded Nanoparticles induce antioxidant activity against oxidative stress. Asian-Australas J Anim Sci. 2016;29(2):288-298.

107. Singh G, Pai RS. Optimized PLGA nanoparticle platform for orally dosed transresveratrol with enhanced bioavailability potential. Expert Opin Drug Deliv. 2014;11(5):647-659.

108. Jung KH, Lee JH, Park JW, et al. Resveratrol-loaded polymeric nanoparticles suppress glucose metabolism and tumor growth in vitro and in vivo. Int J Pharm. 2015;478(1):251-257.
109. da Rocha Lindner G, Khalil NM, Mainardes RM. Resveratrol-loaded polymeric nanoparticles: validation of an HPLC-PDA method to determine the drug entrapment and evaluation of its antioxidant activity. Sci World J. 2013;2013:506083.

110. Karthikeyan S, Prasad NR, Ganamani A, Balamurugan E. Anticancer activity of resveratrol-loaded gelatin nanoparticles on NCI-H460 nonsmall cell lung cancer cells. Biomed Prev Nutr. 2013;3(1):64-73.

111. Chen J, Wei N, Lopez-Garcia M, et al. Development and evaluation of resveratrol, Vitamin E, and epigallocatechin gallate loaded lipid nanoparticles for skin care applications. Eur J Pharm Biopharm. 2017; 117:286-291.

112. Sessa M, Tsao R, Liu R, Ferrari G, Donsì F. Evaluation of the stability and antioxidant activity of nanoencapsulated resveratrol during in vitro digestion. J Agric Food Chem. 2011;59(23):12352-12360.

113. Kumar R, Kaur K, Uppal S, Mehta SK. Ultrasound processed nanoemulsion: a comparative approach between resveratrol and resveratrol cyclodextrin inclusion complex to study its binding interactions, antioxidant activity and UV light stability. Ultrason Sonochem. 2017; 37:478-489.

114. Peng HL, Xiong H, Li JH, et al. Vanillin cross-linked chitosan microspheres for controlled release of resveratrol. Food Chem. 2010;121(1): 23-28.

115. Mamadou G, Charrueau C, Dairou J, Limas Nzouzi N, Eto B, Ponchel G. Increased intestinal permeation and modulation of presystemic metabolism of resveratrol formulated into self-emulsifying drug delivery systems. Int J Pharm. 2017;521(1-2):150-155.
Drug Design, Development and Therapy

\section{Publish your work in this journal}

Drug Design, Development and Therapy is an international, peerreviewed open-access journal that spans the spectrum of drug design and development through to clinical applications. Clinical outcomes, patient safety, and programs for the development and effective, safe, and sustained use of medicines are the features of the journal, which

\section{Dovepress}

has also been accepted for indexing on PubMed Central. The manuscript management system is completely online and includes a very quick and fair peer-review system, which is all easy to use. Visit http://www.dovepress.com/testimonials.php to read real quotes from published authors. 